\title{
Three-tier stratification for CNS COVID-19 to help decide which patients should undergo lumbar puncture with CSF analysis: a case report and literature review
}

\author{
JAHANAVI M. RAMAKRISHNA ${ }^{1}$, CLAUDIA R. LIBERTIN ${ }^{1}$, JASON SIEGEL ${ }^{2}$, \\ MATTHEW J. BINNICKER ${ }^{3}$, DANA HARRIS ${ }^{4}$, GAUTAM V. MATCHA ${ }^{4}$, \\ THOMAS CAULFIELD ${ }^{5}$, W. D. FREEMAN ${ }^{6}$ \\ ${ }^{1}$ Division of Infectious Diseases, Mayo Clinic, Jacksonville, Florida \\ ${ }^{2}$ Departments Critical Care, Mayo Clinic, Jacksonville, Florida \\ ${ }^{3}$ Division of Clinical Microbiology, Mayo Clinic, Rochester, Minnesota \\ ${ }^{4}$ Department of Internal Medicine, Mayo Clinic, Jacksonville, Florida \\ ${ }^{5}$ Departments of Neuroscience and Health Science Research, Mayo Clinic, Jacksonville, Florida \\ ${ }^{6}$ Department of Neurology, Mayo Clinic, Jacksonville, Florida
}

\begin{abstract}
The COVID-19 pandemic continues to overwhelm global healthcare systems. While the disease primarily causes pulmonary complications, reports of central nervous system (CNS) involvement have recently emerged ranging from encephalopathy to stroke. This raises a practical dilemma for clinicians as to when to pursue neuroimaging and lumbar tap with cerebrospinal fluid (CSF) analysis in COVID-19 patients with neurological symptoms. We present a case of an encephalopathic patient infected with SARS-CoV-2 with no pulmonary symptoms. We propose a three-tier risk stratification for CNS COVID-19 aiming to help clinicians to decide which patients should undergo CSF analysis. The neurological examination remains an integral component of screening and evaluating patients for COVID-19 considering the range of emerging CNS complications.
\end{abstract}

Key words: COVID-19, SARS-CoV-2, encephalitis, lumbar puncture, cerebral spinal fluid.

\section{INTRODUCTION}

First detected in Wuhan, China, in December 2019, the SARS-CoV-2 virus (the virus which causes COVID-19) has thus far iinfected more than 6.5 million patients globally [1]. Although the common clinical manifestations arise as a consequence of pulmonary involvement, inflammatory state, and hypercoagulation, case of CNS involvement in COVID-19 have been reported [2,3]. Research on previous human coronaviruses $(\mathrm{HCoV})$, including SARS-CoV-1 and MERS-CoV, suggest that this family of viruses can affect the neurological system, and that SARS-CoV-2 has unique neurotropism and neurovirulence factors [3-6].

Reported neurological symptoms range from non-specific problems commonly seen in sepsis and ARDS (encephalopathy, weakness, myalgias) to problems that commonly occur in the general population, many of whom may also coincidentally be infected with SARS-CoV-2 (stroke). The clinician must make the judgement to pursue further neurological diagnostics such as neuroimaging or CSF analysis. We present a case of an encephalopathic patient found to be infected with SARS-CoV-2 whose primary symptoms were neurological, rather than pulmonary. This diagnosis was confirmed with a lumbar puncture (LP) and CSF analysis.
There are unique challenges in performing lumbar punctures in COVID-19 patients, including usage of personal protective equipment, position dependent hypoxia, anticoagulation for disseminated intravascular coagulation, and provider safety. We illustrate the key features that could warrant CSF analysis, and we offer a three-tiered risk stratification for COVID-19 patients with CNS symptoms who may need an LP in the face of these challenges.

\section{CASE REPORT}

A 90-year-old male with hypertension, stroke, diabetes mellitus type 2, chronic kidney disease, and residing in an assisted living facility presented to the emergency department (ED) with onset of multiple falls and generalized weakness. His neurological exam, including mental status exam, was normal. Baseline labs, chest x-ray (CXR), CT brain, and EKG were unremarkable. He was discharged with supportive care to his facility. Four days later, he returned with worsening of generalized weakness, inability to mobilize, several additional falls, and loss of appetite. No history of fever, chills, cough, or diarrhea was noted. His son confirmed that he is usually functional and independent with mild memory problems. No travel 
or contact exposure to COVID-19 was identified. On examination, he was ill-appearing, dehydrated, and disoriented. Auscultation of lungs revealed focal crackles. Creatinine and BUN were elevated at $2.46 \mathrm{mg} / \mathrm{dl}$ and $62 \mathrm{mmol} / \mathrm{L}$. He was anemic with a hemoglobin of $12.3 \mathrm{~g} / \mathrm{dl}$. C-reactive protein was $13.7 \mathrm{mg} / \mathrm{L}$ (normal $<8.0 \mathrm{mg} / \mathrm{L}$ ). No ferritin or IL-6 levels were performed. CXR was normal except for elevation of the left hemidiaphragm.

The patient was hospitalized but continued to deteriorate, becoming increasingly somnolent and lethargic. He was diagnosed with metabolic encephalopathy. He was oriented only to the person, with poor attention and cooperation, and with no other focal neurological deficits. Magnetic resonance imaging (MRI) showed evidence of his chronic parietal stroke with no new acute changes (Figure 1). Electroencephalogram (EEG) showed low amplitude electrical activity and slowing on background frequencies consistent with encephalopathy. No epileptiform or periodic discharges were seen. The patient received thiamine replacement and empiric ceftriaxone for possible pneumonia due to suspicion of aspiration pneumonia. His renal function exposure to a COVID-19 positive resident at his facility and declining health status. SARS CoV-2 infection was confirmed by reverse transcriptase PCR (RT-PCR) using the cobas ${ }^{\circledR}$ SARS-CoV-2 assay (Roche Diagnostics, Indianapolis, IN) performed on a nasopharyngeal (NP) swab. A repeat CXR showed typical findings of COVID viral pneumonia not present on the two prior CXRs (Figure 2). He remained afebrile and his blood cultures were negative. An LP was performed in appropriate PPE. The basic CSF analysis showed mild pleocytosis (7\% neutrophils, absolute neutrophil count 0.1 ) and a normal protein level. IgG index and oligoclonal band detection were not done. The patient's CSF was tested using a research laboratory test and regained baseline neurological functions two weeks after admission to the hospital. Repeat RT-PCR from NP swabs were positive for SARS CoV-2 two weeks after his neurological recovery. After repeat two slowly normalized with aggressive hydration, but he showed no neurological improvement.

A week later, the patient was retested for SARS-CoV-2 despite being negative on admission due to a possible and was negative for SARS-CoV-2 [7]. This SARS-CoV-2 test had been fully validated for upper and lower respiratory samples, but not CSF specimens.

He was treated with supportive care without experimental or off-label COVID-19 treatments. He slowly improved, sequential negative COVID-19 NP tests in 48 hours, he was discharged.

\section{DISCUSSION}

Neurologic involvement of COVID-19 is being increasingly reported, with symptoms and diagnoses commonly seen in sepsis, ARDS, and generally hospitalized patients. Furthermore, COVID-19 may present without any of the more commonly reported findings of pulmonary involvement, hyperinflammation, or hypercoagulability. Additionally, recognition of this virus as a potential cause of neurological disease, in the absence of pulmonary congestion is relevant to understanding its spectrum of disease [8]. This case report illustrates the difficulty in identifying CNS COVID-19. We propose a systematic way of risk-stratifying patients with potential CNS COVID-19 (Table 1).

Desforges et al. have reviewed various mechanisms to consider for $\mathrm{HCoV}$ neuroinvasiveness, but several questions remain [4]. One hypothesis is that COVID-19 anosmia is due to the localized infiltration of the cribriform plate and nerve fiber disruption, potentially leading to spread into CNS (similar to respiratory syncytial virus and influenza). Previous studies show the ability of SARS-COV-1 to cause neuronal death in mice by invading the brain via the nose close to the olfactory epithelium [9].

Virus-ridden particles inhaled by humans attach to throat and laryngeal cells. These cells have large numbers of angiotensin-converting enzyme 2 (ACE2) receptors, which are known receptors for SARS-CoV-2 [9]. ACE2 receptors are not only prevalent in the lung and enteric tract, but also widespread throughout the brain [10].

Mao et al. conducted a retrospective analysis of 114 patients infected with SARS-CoV-2 and found that 78 patients had neurologic manifestations [11]. In a recent observational study by Helms et al., 49 out of 58 consecutive patients admitted due to acute respiratory distress syndrome associated with COVID-19 presented with neurological signs during clinical course [14]. Neurological symptoms that have been reported include: (i) nonspecific symptoms e.g. headache, fatigue, and encephalopathy, (ii) cerebral hemorrhage, (iii) cerebral infarction (iv) encephalopathy, (v) loss of consciousness, and (vi) skeletal muscle injury and myositis $[3,11,13]$. Since subtle symptoms can go unnoticed by providers concentrating on pulmonary issues, we propose a low-threshold to engage neurologists for detailed neurological assessment. We believe that a thorough neurological history and exam are necessary to direct further investigations (Table 1). Furthermore, patients who are PCR negative, but in high risk demographics (living in crowded facilities, immunosuppression, age, other comorbidities) should also be thoroughly examined and considered for lumbar puncture. 

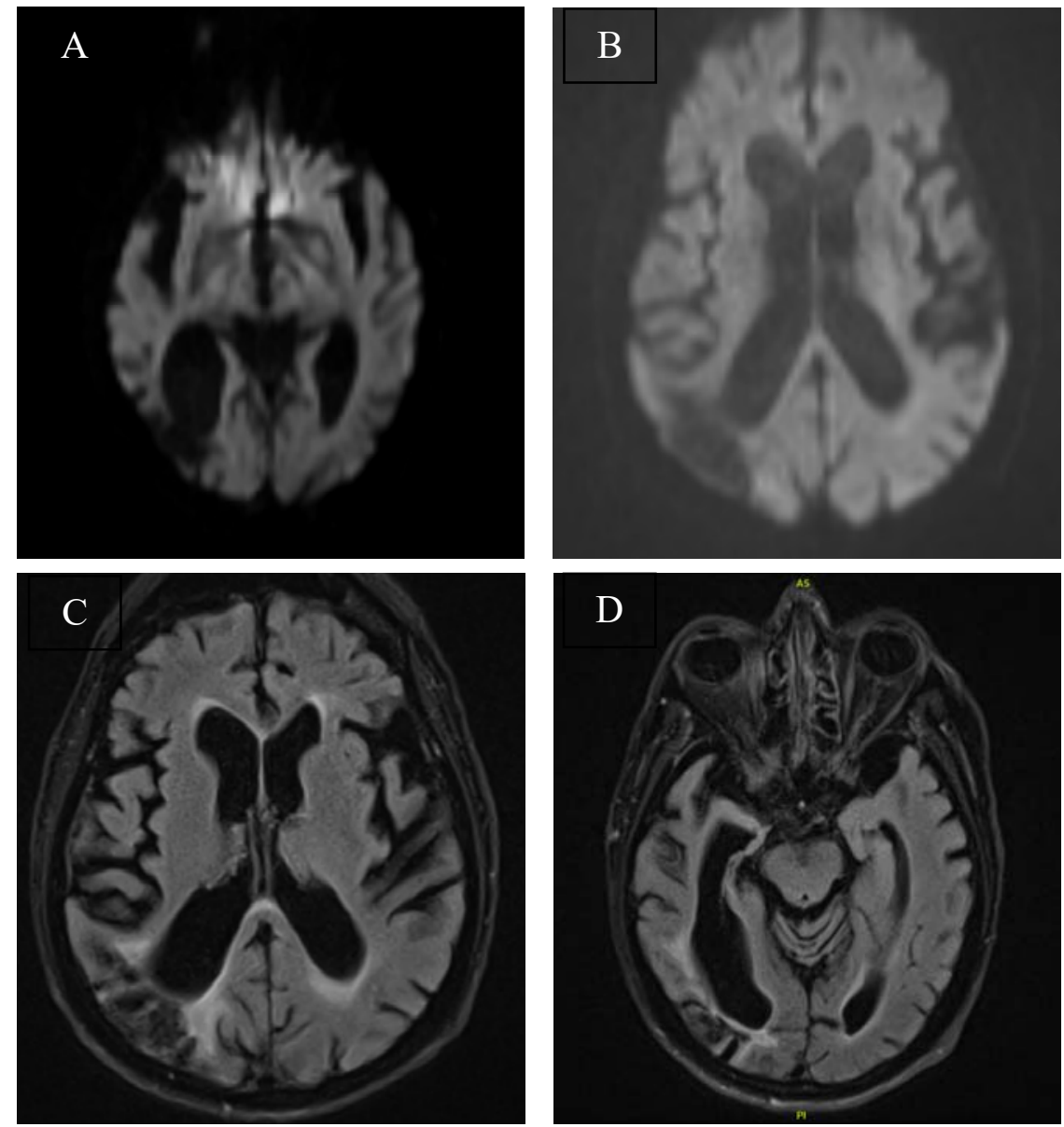

Figure 1. MRI Brain a) diffuse weighted image (DWI) inferior slice showing no acute stroke changes only areas of chronic parietal stroke b) shows similar no new stroke only chronic strokes of the right parietal and left temporal lobes c) FLAIR sequences inferior cut of chronic right parietal stroke and d) FLAIR sequences infecrior cut of chronic right parietal stroke. There is an area of encephalomalacia in the left temporal region, consistent with the history of embolic stroke. No gross changes of encephalitis visible.

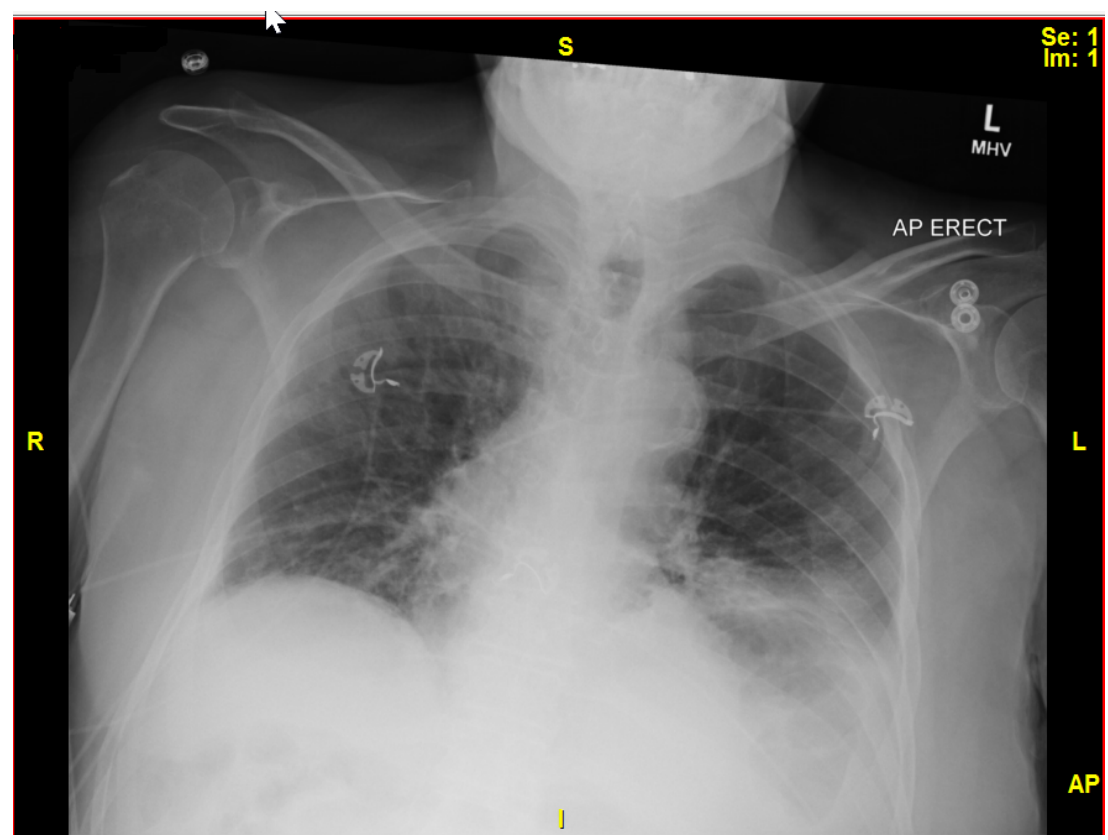

Figure 2. Anteroposterior chest $\mathrm{x}$-ray showing alveolar and interstitial opacities scattered throughout the right lung suggestive of COVID-19. 
Table 1

Three-tier risk stratification of patients at risk for COVID-19 neurological disease in LP and CSF decision-making

\begin{tabular}{l|ll|l}
$\begin{array}{l}\text { Risk Level CNS } \\
\text { COVID-19 }\end{array}$ & \multicolumn{1}{c}{ Patient Characteristics } & LP Indication \\
\hline Low & $\bullet$ & SARS-CoV-2 + with no neurological symptoms & LP not indicated \\
\hline \multirow{2}{*}{ Moderate } & $\begin{array}{l}\text { SARS-CoV-2 +, headache, mild confusion (GCS 13-15), anosmia, loss of } \\
\text { taste, OR }\end{array}$ & $\begin{array}{l}\text { High risk patients (reside in ALF, SNF, or similar facility, age }>60 \text { years } \\
\text { old, baseline pulmonary or cardiovascular comorbidities, } \\
\text { immunosuppressed) SARS-CoV-2 - with these symptoms }\end{array}$ & LP may be indicated \\
\cline { 2 - 4 } High & $\bullet \begin{array}{l}\text { SARS-CoV-2 +, GCS <13, seizure, focal deficits, meningismus, suspicious } \\
\text { MRI findings not attributable to previously existing conditions } \\
\text { (leptomeningeal enhancement, T2 parenchymal hyperintensities, SWI } \\
\text { changes suggestive of hemorrhage) }\end{array}$ & LP indicated \\
\hline
\end{tabular}

Abbreviations: LP, lumbar puncture; CSF, cerebrospinal fluid; GCS, Glasgow Coma Score; SWI, susceptibility-weighted imaging; ALF, assisted living facility; SNF, skilled nursing facility

Our patient did not have SARS-CoV-2 in his $\mathrm{CSF}$, but the pleocytosis suggested some degree of inflammation. Currently, molecular testing for SARS-CoV-2 in CSF has yet to be endorsed by the FDA and CDC, and most medical microbiology laboratories have not validated this sample type. SARS-CoV-2 has only been reported as detected in CSF in two cases, and it is unknown whether the virus can cross the blood brain barrier [2, 13]. The neurological symptoms and diagnoses of CNS COVID-19 are likely due to the same systemic consequences of the virus. Hyperinflammation and hypercoagulability could contribute to encephalopathy, seizures, vasculitis, and strokes.

Finally, clinicians need to implement diagnostic stewardship when performing LPs in a COVID-19 patient. For those requiring LPs, CDC guidelines advise that both patient and the clinician performing the LP use PPE, a scarce commodity [15]. Nevertheless,
LP should be considered when clinically appropriate to exclude other etiologies given that CNS involvement has been proven a predictor of poor clinical outcome in COVID-19 patients [11]. Risk stratification is key to determining which patient should be evaluated more closely for neurological manifestations of COVID-19.

\section{CONCLUSION}

COVID-19 pandemic has a range of emerging CNS complications. COVID-19 encephalopathy could either be nonspecific or a result of viral neuroinvasion. More research is needed to establish SARS-CoV-2's effects on the CNS. A risk stratification of patients at risk for COVID-19 neurological disease and when to do CSF diagnostic molecular testing is enlightening. Greater recognition of the neurological findings and LP with CSF testing may be indicated in selected patients.

Pandemia COVID-19 continuă să copleşească sistemele de sănătate din intreaga lume. Deşi boala cauzează complicaţii pulmonare, totuşi au fost raportate şi cazuri cu afectare SNC de la encefalopatie la atac vascular cerebral. Acest aspect implică o dilemă pentru clinicieni pentru a putea şti când să ceară investigaţii neuroimagistice şi puncţie lombară la pacienţi cu COVID-19. Prezentăm cazul unui pacient cu encefalopatie COVID-19 färă simptome pulmonare. Propunem o clasificare a riscului a pacientilor cu simptome neurologice COVID-19 pentru a putea şti la cine trebuie realizată puncţie lombară.

Correspondence to: Claudia R. Libertin, MD, CPE Mayo Clinic 4500 San Pablo Rd Davis 4E Jacksonville, FL 32224 Phone 904-953-2419

Fax 904-953-0017

E-mail: libertin.claudia@mayo.edu

Acknowledgements: No acknowledgements.

Consent: Written consent obtained by the patient

Conflict of interest disclosure: The authors declare no conflicts of interest.

Funding disclosures: The authors report no funding to disclose. 


\section{REFERENCES}

1. Johns Hopkins University Center for Systems Science and Engineering. Operations Dashboard for ArcGIS. COVID-19 Dashboard by the Center for Systems Science and Engineering (CSSE) at Johns Hopkins University 2020. https://gisanddata.maps.arcgis. com/apps/opsdashboard/index.html\#/bda7594740fd40299423467b48e9ecf6.

2. MORIGUCHI T, HARII N, GOTO J, HARADA D, SUGAWARA H, TAKAMINO J, et al. A first Case of Meningitis/Encephalitis associated with SARS-Coronavirus-2. International Journal of Infectious Diseases 2020.

3. POYIADJI N, SHAHIN G, NOUJAIM D, STONE M, PATEL S, GRIFFITH B. COVID-19-associated Acute Hemorrhagic Necrotizing Encephalopathy: CT and MRI Features. Radiology 2020:201187.

4. DESFORGES M, LE COUPANEC A, DUBEAU P, BOURGOUIN A, LAJOIE L, DUBE M, et al. Human Coronaviruses and Other Respiratory Viruses: Underestimated Opportunistic Pathogens of the Central Nervous System? Viruses 2019; 12:14.

5. STEARDO L, STEARDO L, ZOREC R, VERKHRATSKY A. Neuroinfection may potentially contribute to pathophysiology and clinical manifestations of COVID-19. Acta Physiologica 2020:e13473.

6. BAIG AM, KHALEEQ A, ALI U, SYEDA H. Evidence of the COVID-19 Virus Targeting the CNS: Tissue Distribution, HostVirus Interaction, and Proposed Neurotropic Mechanisms. ACS Chemical Neuroscience 2020.

7. RODINO KG, ESPY MJ, BUCKWALTER SP, WALCHAK RC, GERMER JJ, FERNHOLZ E, et al. Evaluation of saline, phosphate buffered saline and minimum essential medium as potential alternatives to viral transport media for SARS-CoV-2 testing. Journal of Clinical Microbiology 2020.

8. PLEASURE SJ, GREEN AJ, JOSEPHSON SA. The Spectrum of Neurologic Disease in the Severe Acute Respiratory Syndrome Coronavirus 2 Pandemic Infection. JAMA Neurology 2020.

9. NETLAND J, MEYERHOLZ DK, MOORE S, CASSELL M, PERLMAN S. Severe Acute Respiratory Syndrome Coronavirus Infection Causes Neuronal Death in the Absence of Encephalitis in Mice Transgenic for Human ACE2. Journal of Virology 2008; 82:7264-75.

10. DOOBAY MF, TALMAN LS, OBR TD, TIAN X, DAVISSON RL, LAZARTIGUES E. Differential expression of neuronal $A C E 2$ in transgenic mice with overexpression of the brain renin-angiotensin system. American Journal of PhysiologyRegulatory, Integrative and Comparative Physiology 2007; 292:R373-81.

11. MAO L, JIN H, WANG M, HU Y, CHEN S, HE Q, et al. Neurologic Manifestations of Hospitalized Patients With Coronavirus Disease 2019 in Wuhan, China. JAMA Neurology 2020.

12. MEHTA P, MCAULEY DF, BROWN M, SANCHEZ E, TATTERSALL RS, MANSON JJ. COVID-19: consider cytokine storm syndromes and immunosuppression. The Lancet 2020; 395:1033-1034.

13. FILATOV A, SHARMA P, HINDI F, ESPINOSA PS. Neurological Complications of Coronavirus Disease (COVID-19): Encephalopathy. Cureus 2020.

14. HELMS J, KREMER S, MERDJI H, CLERE-JEHL R, SCHENCK M, KUMMERLEN C, et al. Neurologic Features in Severe SARS-CoV-2 Infection. New England Journal of Medicine 2020.

15. SIEGEL JD, RHINEHART E, JACKSON M, CHIARELLO L. 2007 (Updated 2019) Guideline for Isolation Precautions: Preventing Transmission of Infectious Agents in Health Care Settings. American Journal of Infection Control 2019; 35:S65-164.

Receieved $17^{\text {th }}$ September 2020 